Mason responded at length to King's points, complaining that he had presented too many different correlations for the audience to grasp at one sitting, pointing out that they are all post hoc deductions and that sunspot cycle fanciers have now had "a hundred years of failure" in attempting to predict weather changes. He stated once again his unwillingness to accept such statistical evidence in the absence of a plausible physical mechanism behind it.

Asked how he had selected the data presented, King replied that they are typical of results obtained by comparing solar activity with published meteorological data, and that in round terms the Appleton team find in $95 \%$ of all the published data they have examined a correlation which could arise only about $2 \%$ of the time by chance. Mason objected that this meant the data were not new, but when pressed by King to say whether meteorologists should throw out the evidence replied "No", agreeing that solar effects must influence the high atmosphere, and asking that the theorists concentrate on explaining those effects before looking "downstairs" in the troposphere.

Two members of the Met Office then described different studies in which rigorous statistical analysis had failed to remove every trace of a solar influence from their data. B. N. Parker surveyed links between the planetary mean geomagnetic index and surface pressure anomalies on a monthly timescale over the Northern Hemisphere, and $\mathrm{C}$. K. Folland looked at relationships between sunspot and other quasicvelic fluctuations and circulation over the British Isles. The evidence seemed to show significant but not dominant solar influences in some stretches of data at least--not a good enough relationship for forecasting purposes, but suggestive for any theorist studying interactions between the Sun and the Earth. Again, the 22 yr cycle reared its head, and meteorologists took some persuading that this is indeed the more basic solar cycle, not just a harmonic of the $11 \mathrm{yr}$ sunspot number cycle. All this, unfortunately, kept the emphasis of the meeting well away from the short term effects of specific solar events on the atmosphere of the Earth, which surely provide a better handle to grasp the physics of what is going on than any number crunching of cycles, quasicycles and pseudo-cycles.

It was left to D. M. Willis (Appleton Laboratory) to summarise possible mechanisms. It might have come as a surprise to meteorologists sceptical of some of King's statistics to learn how much room there is to doubt astrophysical ideas about the Sun and the constancy of the solar parameter. Among many speculations aired before, Willis rightly emphasised the newer ideas of the influence of solar proton events on the atmosphere. This work is closely related to the study by Reid et al. (Nature, 259, 177; 1976) of faunal extinctions at times of magnetic reversals, and suggests that solar cycle influences on the weather may be the accumulation of solar proton effects on the ozone layer. It is also clear, however, that the state of the art in measuring the solar parameter is not yet good enough to rule out the possibility of a change by $\pm 1 \%$ over the solar cycle, changing mean global surface temperatures by $\pm 1 \mathrm{~K}$.

The overall flavour of the meeting seems clear. Solar-Terrestrial relationships affecting the weather are real, but not dominant, and are not well enough understood for their use in Met Office forecasts as yet. But they may provide clues of great value to astronomers investigating the nature of the Sun and solar wind. This explains, perhaps, the apparent rift between meteorologists and space physicists; in fact, they are essentially in agreement on the reality of the link. but view it from very different positions.

\section{Let booming sands boom}

\section{from Peter J. Smith}

HARDLY surprisingly in view of their weird effects, sounding sands are incorporated into folklore and legends going back at least 1,500 years. Not that our ancestors were always listening to the same sounds. The most common of the musical sediments is probably squeaking (otherwise known as singing, barking or whistling) sand which produces a high frequency note in the range $500-2,500 \mathrm{~Hz}$. But there is also screeching sand which emits an even higher frequency note $(>2,500$ $\mathrm{Hz}$ ) reminiscent of that produced by rubbing a finger around the top of a wine glass; and at the other end of the scale, low frequency booming sand can give rise to a sound like thunder which under ideal conditions can be heard up to $10 \mathrm{~km}$ from its source. The essential condition for the production of sound is either natural or forced movement; still sand is inevitably silent sand.

A recent paper by Criswell et al. (J. geophys. Res., 80, 4963; 1975) investigates booming sand, which generates not only acoustic but also seismic waves. Both emissions are produced by natural slumping of the sand, although they may also be produced manually in short bursts by digging in the sand, by forcing it downhill or even by walking on it. The natural slumping of an area of many square metres of sand may persist up to 15 min, giving rise to a 'roar', or on occasions a 'hum', rather like the sound of a low-flying propeller aircraft. But whatever the sound, it is always accompanied by ground vibrations which can be felt through the feet of anyone standing on or near a booming dune and through the fingers of someone generating artificial booming by digging in the sand. One observer has compared such vibrations to a mild electric shock from household current (50-60 Hz).

Though not particularly common, booming dunes have been reported at more than 30 sites in all continents except Antarctica and, curiously, Australia. The sound frequencies at some of these sites have been estimated before by reference to pitch pipes; but Criswell et al. have now carried out the first simultaneous measurement of acoustic and seismic spectra from a booming dune (Sand Mountain in Nevada) using, respectively, air microphones and geophones. The emissions were generated artificially by digging holes in the sand with a flat-bladed shovel.

Not entirely unexpectedly, the scientific aspects of booming dunes turn out to be rather dull and hardly a match for the subterranean ghosts, the shoeing of horses in underground caverns and the clanging of bells in buried monasteries to which sand sounds have been attributed in the past. The most "significant finding" is that the frequency spectrum of a short $(<2 \mathrm{~s})$ forced booming event comprises sharp peaks largely in the range $50-80 \mathrm{~Hz}$ for both acoustic and seismic emissions. These results throw little light on the mechanism by which the vibrations are generated, which remains unclear; nor do they do much to justify the original aim of the work, which was to see whether a similar mechanism on the Moon could account for surface moonquakes.

Criswell and his colleagues do obtain one interesting result, however. A comparison of an acoustic amplitude trace from a Sand Mountain note with the trace of an $88-\mathrm{Hz}$ organ tone from the opening stanza of Bach's C-Minor Passacaglia and Fugue shows that sand and expertly crafted organ pipes produce notes of comparable purity.

Perhaps Criswell and others should take the hint from Walt Whitman who, tiring of the learn'd astronomer's proofs, figures and charts, "wander"d off ... in the mystical moist nightair, and from time to time, look'd up ... at the stars." 